\title{
The Effectiveness of Hymes' Ethnography of Communication Theory to Teach English Learners' Reading Comprehension Ability: A Discoursal Approach
}

\author{
Reza Ebrahimi ${ }^{\mathrm{a}}$, Parisa Farrokh *b \\ ${ }^{a, b}$ English Translation Department, Lahijan Branch, Islamic Azad University, Lahijan, Iran
}

\begin{abstract}
The aim of this study was to investigate the effect of discoursal approach on Iranian intermediate EFL learners' reading comprehension ability. Quick Placement Test (QPT) was used to select 60 intermediate EFL learners as the participants of this study. Then, they were randomly divided into experimental and control groups. Each consisted of 30 learners. Prior to the treatment, the participants of both groups were given a pretest to ensure their reading comprehension. The experimental group was exposed to the Hymes' model. In the control group the researcher used placebo for teaching reading skill. Then a posttest was administered to both groups. An Independent samples t-test between posttests of the study and a paired-samples t-test between the pretest and posttest of the groups of the study were run. The results of the study revealed and emphasized that the Hymes' model improved the learners' reading comprehension.
\end{abstract}

Keywords: Discourse, Sociolinguistics, Ethnography of Communication, Hymes’ Model

\section{Introduction}

Reading is considered as an effective learning instrument for creating meaning and attaining new knowledge (Pretorius, 2002). Many scholars emphasized the power of reading. According to Ashton (2012), reading comprehension proficiency is very significant for academic success. Through reading, people can have a better view of the world and acquire wisdom. Reading is considered as an essential tool to acquire from a subject and a basic skill upon which all formal education depends $(\mathrm{Su}, 2006)$. Since most of what is needed to be known is communicated via the written mode so reading skill has a significant role in second/foreign language learning. Because of the crucial role of reading skill teachers should search for finding best ways to equip their teaching procedure, techniques and resources to 
improve in the field of reading, as well. Nowadays, views of reading theory have changed noticeably that reading is no longer seen as little more than reinforcement for oral language instruction.

Psycholinguistic research has primarily investigated language comprehension at the level of words and sentences, i.e. discourse (Traxler \& Gernsbacher, 2006). Understanding discourse, however, requires much more than processing a series of individual sentences. Researches on discourse comprehension have emphasized the critical role of discourse context in building meaning from extended linguistic input, and have tried to characterize the various psychological processes involved in discourse experiences (Gerrig, 1993; Graesser, Gernsbacher, \& Goldman, 2003). Historically, research in discourse processing has examined the factors that influence comprehension and memory for text. Text content has considerable impact on readers' comprehension.

According to Long (1996) and Lyster (2007), classroom discourse plays a critical role in second language learning. The instructional exchanges between teacher and students provide opportunities for the learners to practice the target language, test out hypotheses about the target language, and obtain useful feedback. Learners' conscious attention to such meanings and forms (i.e. noticing) is necessary for language learning. The situations typically occur when the teacher and learners negotiate the meanings of the target words or when the learners notice the gap between what they want to say and what they can produce during classroom interaction.

The teacher's input is equally important for learners to learn the target words. Laufer and Hulstijn (2001) further suggest that learners learn by searching for and locating information on the meanings or forms of the words. Instructional scaffolding that leads learners to make associations of the target words with other lexical items, grammatical forms, syntactical structures, and contextual meanings improve learners' depth of processing of the target words. As Laufer and Hulstijin (2001) aptly suggested, it is the frequency and quality of processing of the meanings of the target words that help learners to remember them.

Concerning this issue, in recent decades' studies on reading comprehension have drawn attention of the scholars in language learning and teaching research such as Nation, 2006, 2013 and 2015; Mehrpour, Razmjoo, and Kian, 2011 in EFL context. But none of them mentioned to the role of discoursal approach on reading comprehension. Hymes (1964) believed that if the readers know about the writer who products the utterance, it will help the readers to imagine what that particular person is likely to say. Hymes was inspired by Noam 
Chomsky's (1965) 'Theory of Linguistic competence and performance'. Chomsky said, primarily the language of an ideal speaker-hearer in a completely homogenous speech community who knows its language perfectly and is unaffected by grammatically irreverent conditions, like as memory imitations, directions, shifts of attention and interest, and errors (random or characteristics) in applying his knowledge of language in actual performance.

Hymes proposed the term 'ethnography of speaking', later amended to 'ethnography of communication', to describe a new approach to understanding language in use (Hymes, 1962, 1964). In doing this, Hymes aimed to move away from considering speech as an abstract model and toward investigating the diversity of speech as it is encountered in ethnographic fieldwork. Thus Hymes offers a theoretical basis for language study that accounts for both linguistic variations from individual to individual and relative linguistic coherence across the social realm. For Hymes, discourse cannot be considered separate from the sociological and cultural factors that help shape linguistic form and create meaning.

According to Hymes the following aspects are considered to the ethnography of communication study:

S-setting and scene. Hymes has considered that "the setting refers to the time and place while scene describes the environment of the situation.

P-Participants. This refers to who is involved in the speech including the speaker and the audience.

E-Ends. The purpose and goals of the speech along with any outcomes of the speech.

A-Act Sequence. The order of events that took place during the speech.

K-key. The overall tone or manner of the speech.

I-Instruments. The form and style of the speech being given.

$\mathrm{N}$-Defines what is socially acceptable at the event.

G-Genre type of speech that is being given.

The importance of this study stems from its attempts to improve students' reading comprehension through Hymes' theory emphasizing on ethnography of communication. To fulfill the purpose of this study, the following research question was proposed:

RQ: Does applying discoursal approach has any statistically significant effect on Iranian intermediate EFL learners' reading comprehension ability?

Based on the research question the following null research hypothesis has been considered:

H0: Applying discoursal approach does not have any statistically effect on Iranian intermediate EFL learners' reading comprehension ability. 


\section{Method}

\section{The Design of the Study}

The current study followed quasi- experimental design in which subjects of the study were non-randomly selected, and were made homogeneous, and then their intact classes were randomly assigned into one control and one experimental group in order to investigate the research question of the study. The following diagram illustrates the steps taken in this study:

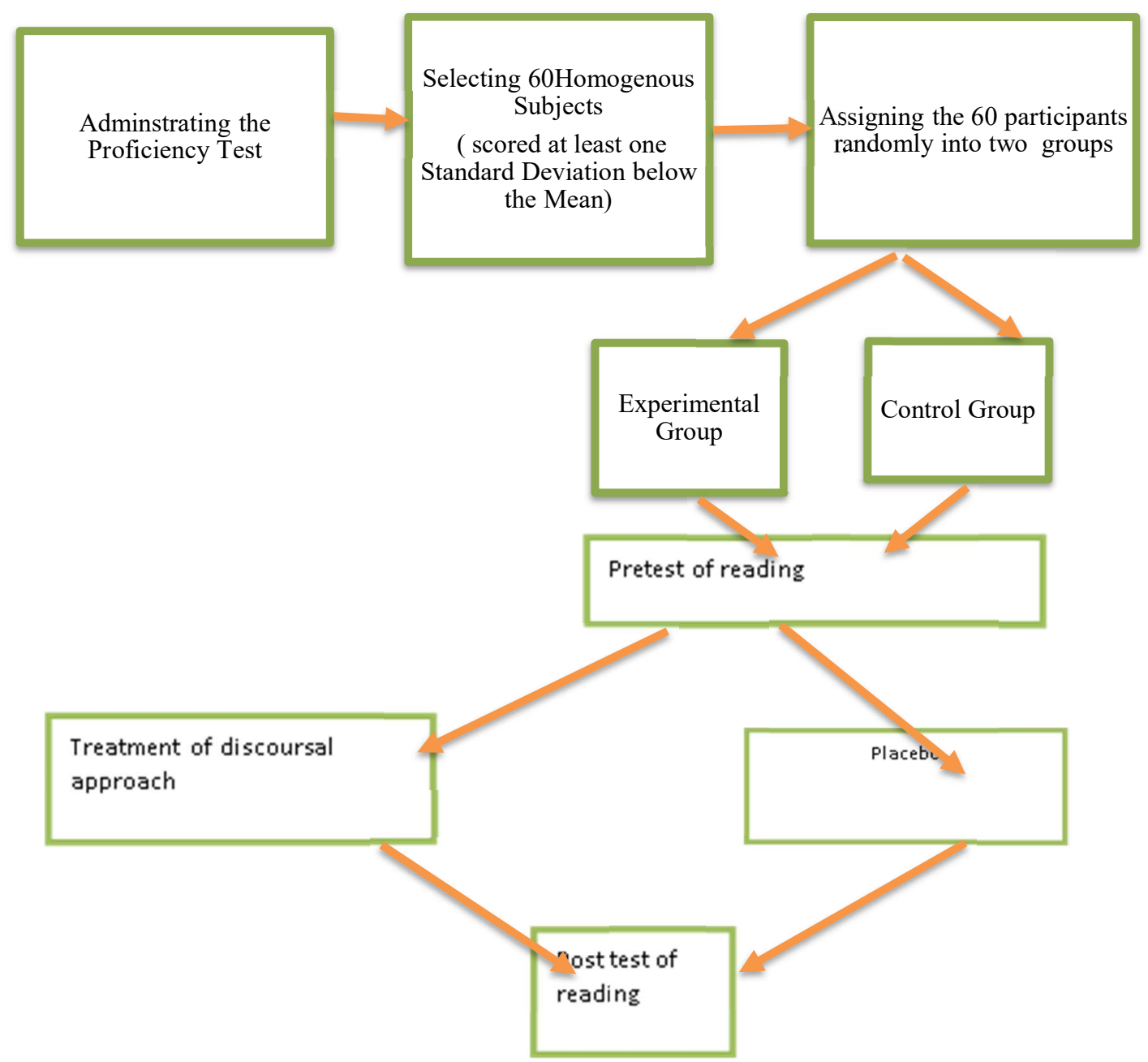

Figure1. The Diagram of the Design of the Study 


\section{Participants}

The study was conducted with 60 Iranian high school students in Langroud, Iran. The participants were all male. The participants were selected from three intact classes. Thirty participants were randomly chosen as the experimental group and 30 with the same characteristics were regarded as the control group. Their age varied from 15 to 16 . In order to make sure of homogeneity, the participants were selected out of 80 intermediate students based on their results in OQPT. Having calculated the mean and the SD, participants with the score of $1 \mathrm{SD}$ above and below the mean (1SD from the mean) were selected to conduct the study. The experimental group received 8-sessions treatment in which they encountered and received discoursal approach treatment. The control group received no treatment, i.e. placebo.

\section{Instrument}

To be sure of the homogeneity in two groups, proficiency test was administrated to establish of participants' homogeneity. Oxford Quick Placement Test (OQPT) was administered to make sure the participants were homogenous in terms of their language proficiency. This enables teachers to have a great understanding of what level their students are at. The test contains 20 multiple choice questions assessing student's knowledge of reading comprehension level, a reading text with 20 graded comprehension questions.

The purpose of this test administered before the treatment was to find the possible initial differences between the knowledge of reading comprehension in the experimental and control groups. In so doing, a reading comprehension test was used to test the participants' knowledge of reading comprehension. This test was taken from "Handbook for the TOEFL Standard Test. Therefore, it was reliable and standard test. The test was utilized to measure the reading comprehension knowledge of the learners in both groups before the treatment. No changes or modifications were made to the test.

A standard and reliable test similar to the pretest was used as posttest after eight sessions of instruction at the end of the treatment. This test which was administered after the treatment sessions was equal in all respects to pretest. In fact, another version of the reading comprehension test from "Handbook for the TOEFL Standard Test" was used to test the participants' knowledge of reading comprehension after the treatment . 


\section{Data Collection Procedure}

This study was conducted in March and April 2018. First, OQPT was administered as the homogenizing tool. It was administered to 80 students. After analyzing the results, 60 intermediate subjects were selected and randomly assigned into experimental and control groups. A pretest of reading comprehension was administered to both groups. The students in two groups received the same reading materials which were taught by the same teacher.

The experimental group received discoursal approach. The study took two months. During this period, the students read eight passages on different subjects. The teacher used Hymes' model for teaching reading texts in experimental group. He analyzed and explained the texts based on Hymes' model. For Hymes, speech cannot be considered separate from the sociological and cultural factors that help shape linguistic form and create meaning, and so the frame he offers in place of grammar gives equal place to both aspects of speech: speech and the entailments that give meaning to speech cannot be considered in isolation. Hymes proposed SPEAKING that includes: S-setting and scene. Hymes has considered that "the setting refers to the time and place while scene describes the environment of the situation. PParticipants. This refers to who is involved in the speech including the speaker and the audience. E-Ends. The purpose and goals of the speech along with any outcomes of the speech. A-Act Sequence. The order of events that took place during the speech. K-key. The overall tone or manner of the speech. I-Instruments. The form and style of the speech being given. N-Defines what is socially acceptable at the event. G-Genre type of speech that is being given. Based on Hymes' model teacher clarified each item for the students in experimental group before they read the text. Here is an example of the text analysis based on Hymes' model.

Settings: The setting is school. Two boys are talking together in the basketball field.

Participants: There are two boys.

Ends: The reading is the conversation between two classmates that one of them is trying to convince another that he is a good basketball player.

Act: The speech acts in turn.

Instrument: The members meet face to face

Norms: There is norm of conversation.

Genre: typical conversation.

The control group received no treatment. In other words, placebo strategy was used. The researcher gave the same reading texts to control group and explained the subject of the reading text before asking students to read it. Then the teacher read the text, focused on new 
vocabularies' meaning and pronunciation and then answered the reading comprehension questions. After the treatment, a posttest of reading comprehension, like pretest was administered to both groups.

\section{Result}

\section{The Pilot Study}

The reliability of the reading comprehension test and Oxford Quick Placement Test(OQPT) were estimated through running Cronbach's Alpha to the results of the tests in a pilot study on (15) students. The results are presented in Table 1.

Table 1. Reliability Statistics for the Reading Comprehension Test and OPT

\begin{tabular}{lrl}
\hline Cronbach's Alpha & N of Items \\
\hline Reading Comprehension Test & .737 & 15 students \\
OQPT & .773 & 15 students
\end{tabular}

The values of reliability were explained according to the reliability standards suggested by Barker, Pistrang, and Elliott (1994). The values of Cronbach's Alpha for the reading comprehension test and OQPT were (.737), and (.773), respectively that were both acceptable indicating that the instruments could be considered as reliable tools for the main study (See Table 2).

Table 2. Suggested Standards for the Reliability Index (Adopted from Barker, Pistrang, and Elliott, 1994)

\begin{tabular}{ll}
\hline Interpretation & Reliability indices \\
Good & .80 \\
Acceptable & .70 \\
Marginal & .60 \\
Poor & .50 \\
\hline
\end{tabular}




\section{Descriptive Findings of the Study}

This section focuses on the descriptive analysis of the obtained data in this study. Such analysis was done by using the SPSS software.

Table (3) shows the descriptive analysis for the pretest and posttest scores of the reading comprehension in the experimental and control groups of the study:

Table 3. Descriptive statistic results of the pretest of both groups on the reading comprehension

\begin{tabular}{lllll}
\hline Variable & $\mathrm{N}$ & Mean & SD & SEM \\
\hline Control & 30 & 16.20 & 2.772 & .506 \\
Experimental & 30 & 16.82 & 2.195 & .415 \\
\hline
\end{tabular}

Table (3) shows the descriptive statistic results of the pretest of the groups of the study. The number of the students in control group was 30 and the mean of this group, the std. Deviation, and the std. Error mean were 16.20, 2.772, .506 respectively. And also the number of students in experimental group, the mean of this group, the std. Deviation, and the std. Error mean were $30,16.82,2.195$, and .415 respectively.

Table 4. Descriptive statistic results of the posttest of both groups on the reading comprehension

\begin{tabular}{lllll}
\hline \multicolumn{1}{c}{ Variable } & $\mathbf{N}$ & Mean & SD & SEM \\
\hline Control & 30 & 16.47 & 2.193 & .400 \\
\hline Experimental & 30 & 18.46 & 1.551 & .293 \\
\hline
\end{tabular}

The question of the study targeted the effect of discoursal approach on Iranian intermediate EFL learners' reading comprehension ability. In this regard, the mean scores of students' performance on each of the two exams as well as the standard deviations were calculated in order to observe the probable change in students' performance before and after the instruction. Table (4) shows the descriptive statistic results of the posttest of the groups of 
the study. The number of the students in control group was 30 and the mean of this group, the std. Deviation, and std. Error mean were 16.47, 2.193, .400 respectively. However, the number of students in experimental group, the mean of this group, the std. Deviation, and std. Error mean were 30, 18.46, 1.551, and .293 respectively.

\section{Inferential Findings of the Study}

The current study was conducted to explore about a hypothesis and in this regard took several theoretical, practical and statistical steps. In order to probe whether the treatment given to the experimental group had made any significant change within this group and to see if the students in this group had performed significantly differently on the posttest compared with the pretest, the reading comprehension pretest and posttest scores of the experimental and control groups were compared by using a paired t-test. The results obtained from this statistical test are summarized in table (5).

Table 5. Paired sample t- test for pre- and posttest in experimental and control groups.

\begin{tabular}{llcccccc}
\hline Group & Pair & Mean & SD & SDE & T & df & Sig (2-tailed) \\
\hline Control & pre-and & -.267 & 1.437 & .262 & -1.017 & 29 & .318 \\
& posttests & & & & & & \\
Experimental pre-and \\
posttests & -1.643 & 1.062 & .201 & -8.189 & 27 & .000 \\
\hline
\end{tabular}

Now, in order to answer the research question, data were analyzed in both control and experimental groups according to above tables. As it is evident from Table (5), there is no significant difference between pre- and posttests in control group $(\mathrm{t}=1.017 ; \mathrm{P}=.318)$ while with regard to the effect of discoursal approach on improving EFL learners' reading comprehension, the results of data analysis (t-test) in table (5) indicates that there is a statistically significant difference between students' performance in reading comprehension in pretest and posttest $(\mathrm{t}=8.189 ; \mathrm{P}=.000)$. On the other hand, by looking at the table (5) subjects scored higher in posttest $(\mathrm{M}=18.46, \mathrm{SD}=1.55)$, when they were taught discoursal approach, then pretest $(\mathrm{M}=16.82, \mathrm{SD}=2.195)$. By taking the results of data analysis into account, the hypothesis, i.e., "Applying discoursal approach does not have any statistically effect on Iranian intermediate EFL learners' reading comprehension ability" is rejected. In other words, discoursal approach could play a significant role in enhancing EFL learners' reading comprehension. 


\section{Discussion \& Conclusion}

The results showed that Hymes' model had significant effects on the reading ability of Iranian EFL intermediate learners. According to the results of this study, it was cleared that discoursal approach was effective.

The findings of the present study are in line with $\mathrm{Wu}$ (2017). He found that readers should adopt an interactive way, that is to say, they should analyze a text in a macro-way, and only in this way, can our readers understand a text more quickly and thoroughly, then their language skills will be improved. Things that our teachers should pay attention to are: First, master abundant language knowledge, such as grammar, lexicology, syntax, linguistics, pragmatics and so on; second, set foot in varied background knowledge, such as cultures both at home and abroad, literatures, philosophy, psychology, anthropology and things alike. All these knowledge is not only beneficial for readers to develop their discourse analysis skills but also helpful to make reading teaching efficient.

Moreover, this study is congruent with the one conducted by Ray and Biswas's (2011) study. Language, communication, and ethnography are interlocked with each other. These three issues have played a great role in human cultural space (HCS) to the society. Communication sometimes controls the individualism and the social status with group solidarity. Their study revealed that the study of ethnography in times and space played as a cognitive device to clarify human social/cultural identity. Ethnography of communication stated the rural simple way of life reflected through people's mode of speaking and their sentiment.

The findings of this study in some ways are in line with Sparks (2004) who investigated the language/discourse comprehension and understanding. Discourse comprehension involves building meaning from extended segments of language, such as novels, news articles, conversations, textbooks, and other everyday materials. Successfully comprehending larger units of text and discourse requires making inferences to connect ideas both within and across local and global discourse contexts. Establishing such connections relies on the integration of information from prior discourse contents, as well as from prior knowledge, in order to build a coherent memory representation for the events and concepts the text describes. Following successful comprehension, the resultant discourse representation can be retrieved, updated, manipulated, and applied in order to answer questions and solve problems. 
In the present study, the advancement was seen from the pretest to the posttest in two groups, i.e. the experimental and the control. In any case, the members in the experimental who used Hymes' model as treatment could comprehend the text contrasted with the control group who got no treatment. Consequently, the consequences of the present study have uncovered that using discoursal approach improves the EFL learners reading comprehension. In any case, the study has demonstrated that the experimental group who used Hymes' model exceeded the control group in their reading comprehension. According to the results of this study, Hymes' model could influence students' reading comprehension ability sufficiently and made statistically significant improvement in the students' reading ability. Generally, the results of the current study demonstrated that comprehension ability can be improved by employing appropriate strategies such as Hymes' model. Hence, the null hypothesis of the research, i.e., "applying discoursal approach does not have any effect on Iranian intermediate EFL learners' reading comprehension ability" was rejected.

This study explored the effects of discoursal approach on Iranian intermediate EFL learners' reading comprehension ability. The findings obtained in this study lead to some pedagogical implications which are beneficial for teachers and learners in an EFL context. Different stakeholders in the field of language learning and teaching such as curriculum and material developers, course and syllabus designers, learners, teachers and teacher trainers can gain positive advantages of the obtained results. Hymes' model as a helpful technique can be administered in English institutes. Using the findings of this study can improve the condition and status of language teaching in the context of Iran. The findings may encourage teachers, who still believe in their own traditional techniques in teaching reading to shift their attitudes and follow more practical techniques.

With regards to the results of the study, Hymes' model has been applied in order to improve the learners' reading ability because it makes reading enjoyable and motivates the learners. It provides an interesting class which captures students' interest. As a result, it helps to achieve a better reading comprehension.

Moreover, the findings of this study may be beneficial for curriculum developers and syllabus designers who provide teaching materials for Iranian English learners should pay more attention to learners' needs and include more examples and varieties of discoursal approach in text books, teaching materials and stuff like that, so that the learners have more opportunities for practicing and using discourse in reading. As a result, massive and considerable improvement on the learners' reading ability can be observed. 


\section{References}

Ashton, A. (2012). Mental Imagery and Reading Comprehension Proficiency in English Second

Language Learners: An Exploratory Study. MA thesis

Chomsky, N. (1965). Aspects of the theory of syntax. USA: MIT Press,

Gerrig, R. J. (1993). Experiencing narrative worlds. New Haven, CT: Yale University Press.

Graesser, A. C., Gernsbacher, M. A., \& Goldman, S. R. (Eds.). (2003). Handbook of discourse processes. Mahwah: Erlbaum.

Hymes, D. (1962). "The Ethnography of Speaking", pp. 13-53 in Gladwin, T. \& Sturtevant, W.C. (eds), Anthropology and Human Behavior, The Anthropology Society of Washington, Washington.

Hymes, D. (1964). Language in culture and society: A reader in linguistics and anthropology. New York: Harper \& Row.

Laufer, B. \& Hulstijn, J. (2001). Incidental vocabulary acquisition in a second language: the construct of task-induced involvement. Applied Linguistics, 22 (1), 1-26.

Long, M. (1996). The role of the linguistic environment in second language acquisition. In W. Ritchie \& T. Bhatia (Eds.), Handbook of second language acquisition (pp. 413-468). San Diego: Academic Press.

Lyster, R. (2007). Learning and teaching languages through content: A counterbalanced approach. Amsterdam: John Benjamins.

Mehrpour, S., Razmjoo, S. A., \& Kian, P. (2011). The Relationship between Depth and Breadth of Vocabulary Knowledge and Reading Comprehension among Iranian EFL Learners. Journal of English language teaching and learning, 2(222), 97-127.

Nation, P. (2006). A vocabulary size test. The Language Teacher, 31(7), 9- 13.

Nation, I. S. P. (2013). How large a vocabulary is needed for reading and listening? The Canadian Modern Language Review, 63, 59-82.

Nation, I. S. P. (2015). Teaching and Learning Vocabulary. Boston: HeinleCengage Learning.

Pretorius, E.J. (2002). Reading and applied linguistics: a deafening silence? Southern African

Linguistics and

Applied Language Studies, 20, 91-103 
Ray, M. \& Biswas, C. (2011). A study on Ethnography of communication: A discourse analysis with Hymes 'speaking model'. Journal of Education and Practice, 2 (6), 33 40.

Sparks, J. (2004) Pragmatics as a theory of linguistic adgpatation)). IPRA Working Docurnent. Antwerp, Belgium: University of Annverp.

$\mathrm{Su}, \mathrm{C}$. (2006). Evaluation of reading skills applied in the first-year college English reading course. Proceedings of the Tenth International Symposium on English Teaching, Taipei, Crane, 579-587.

Traxler, M. J., \& Gernsbacher, M. A. (2006). Handbook of psycholinguistics (2nd ed.). San Diego, California: Academic Press.

$\mathrm{Wu}, \mathrm{Y}$. (2017). Application and teaching implication of discourse analysis in reading comprehension. Advances in Intelligent Systems Research, 156, 513-517. 